\title{
ANTISSEPSIA CIRÚRGICA DAS MÃOS COM PREPARAÇÃO ALCOÓLICA: REDUÇÃO MICROBIANA EM DIFERENTES TEMPOS DE USO NO CENTRO CIRÚRGICO
}

\author{
Surgical hand antisepsis with alcohol solution: \\ microbial reduction at different application times in the surgical center \\ Antisepsia quirúrgica de las manos con preparación alcohólica: \\ reducción microbiana en diferentes tiempos de uso en el centro quirúrgico \\ Juliana Gil Prates Peixoto ${ }^{1 D}$, Aline Branco ${ }^{2}$ (D) Cícero Armídio Gomes Dias ${ }^{3}$ (D), \\ Luzia Fernandes Millão ${ }^{4}$ D, Rita Catalina Aquino Caregnato ${ }^{5 *}$ (D)
}

RESUMO: Objetivo: Avaliar a redução microbiana após antissepsia cirúrgica das mãos dos cirurgiões, realizada com preparação alcoólica, em diferentes tempos. Método: Estudo de prevalência, pragmático, de campo, realizado em hospital terciário do Brasil. Coletaram-se amostras microbiológicas das mãos de 54 cirurgiões após lavagem simples, para determinar a flora microbiana basal e, após a antissepsia cirúrgica alcoólica, para avaliar a redução microbiana imediata. Categorizaram-se os resultados da redução microbiana em redução leve (até 50\% de redução da flora bacteriana), moderada (de 51 a $80 \%$ ) e alta (acima de 80\%). A pesquisa foi submetida e aprovada pelo Comitê de Ética e Pesquisa da instituição hospitalar privada, sede do estudo, e da instituição de ensino superior federal. Resultados: Nas técnicas realizadas em menos de 90 segundos, houve $80 \%$ de redução severa, 6,7\% de redução moderada e 13,3\% de redução leve. Nas técnicas desempenhadas em mais de 180 segundos, todas as amostras apresentaram redução de contagem bacteriana, o que não ocorreu em tempos menores de antissepsia. Conclusão: Quando a técnica e o tempo recomendados são seguidos, maior é a redução bacteriana, em comparação aos tempos menores.

Palavras-chave: Antissepsia. Contagem de colônia microbiana. Desinfecção. Desinfecção das mãos. Procedimentos cirúrgicos operatórios.

ABSTRACT: Objective: To evaluate the microbial reduction after surgical hand antisepsis performed with alcohol solution at different application times among surgeons. Method: This is a pragmatic prevalence field study carried out in a Brazilian tertiary hospital. Microbiological samples were collected from the hands of 54 surgeons after simple washing to determine the baseline microbial flora and after surgical antisepsis with an alcohol solution to evaluate the immediate microbial reduction. We categorized the microbial reduction results as mild (up to $50 \%$ bacterial flora reduction), moderate ( 51 to $80 \%$ ), and high (more than $80 \%$ ). The research was submitted to and approved by the Research Ethics Committee of the private hospital (study site) and the federal institution of higher education. Results: Techniques performed in less than 90 seconds showed an $80 \%$ high reduction, $6.7 \%$ moderate reduction, and $13.3 \%$ mild reduction. In applications that lasted more than 180 seconds, all samples presented bacterial count reduction, which did not occur in shorter antisepsis times. Conclusion: When the recommended technique and time are followed, the bacterial reduction is greater compared to lower durations.

Keywords: Antisepsis. Colony count, microbial. Disinfection. Hand disinfection. Surgical procedures, operative.

\footnotetext{
'Mestre em Ensino na Saúde pela Fundação Universidade Federal de Ciências da Saúde de Porto Alegre (UFCSPA). Enfermeira Especialista em Controle de Infecção e Segurança do Paciente da Unimed Porto Alegre (RS), Brasil.

Enfermeira residente do Programa de Residência Multiprofissional em Saúde, Atenção ao Paciente Crítico do Grupo Hospitalar Conceição - Porto Alegre, RS, Brasil. ${ }^{3}$ Doutor em Ciências (Microbiologia) pela Universidade Federal do Rio de Janeiro. Professor associado da UFCSPA - Porto Alegre (RS), Brasil.

¿Doutora em Psicologia pela Universidade Pontifícia de Salamanca. Professora adjunta do Departamento de Enfermagem e do Mestrado Profissional em Ensino na Saúde da UFCSPA - Porto Alegre (RS), Brasil. ${ }^{5}$ Doutora em Educação pela Universidade Federal do Rio Grande do Sul. Professora adjunta do Departamento de Enfermagem da UFCSPA - Porto Alegre (RS), Brasil.

*Autora correspondente: ritac.ufcspa@gmail.com

Recebido: 19/01/2020 - Aprovado: 05/04/2020

DOI: 10.5327/Z1414-4425202000020004
} 
RESUMEN: Objetivo: evaluar la reducción microbiana después de la antisepsia quirúrgica de las manos de los cirujanos, realizada con preparación alcohólica, en diferentes momentos. Método: Estudio pragmático de prevalencia de campo realizado en un hospital terciario de Brasil. Muestras microbiológicas recogidas de las manos de 54 cirujanos después de un simple lavado, para determinar la flora microbiana basal y después de la antisepsia quirúrgica alcohólica, para evaluar la reducción microbiana inmediata. Los resultados de la reducción microbiana se clasificaron como leves (hasta un 50\% de reducción en la flora bacteriana), moderados (del 51 al 80\%) y altos (más del 80\%). La investigación fue presentada y aprobada por el Comité de Ética e Investigación de la institución del hospital privado, sede del estudio y de la institución federal de educación superior. Resultados: en las técnicas realizadas en menos de 90 segundos hubo una reducción severa del 80\%; 6,7\% de reducción moderada; 13,3\% de ligera reducción. En las técnicas realizadas durante 180 segundos, todas las muestras presentaron una reducción en el recuento bacteriano, lo que no ocurrió en tiempos de antisepsia más cortos. Conclusión: Cuando se siguen la técnica y el tiempo recomendados, mayor es la reducción bacteriana, en comparación con los tiempos más cortos. Palabras clave: Antisepsia. Recuento de colonia microbiana. Desinfección. Desinfección de las manos. Procedimientos quirúrgicos operativos.

\section{INTRODUÇÃo}

As infecções relacionadas à assistência à saúde (IRAS) são importantes eventos adversos aos quais os pacientes estão expostos, representando relevantes indicadores da qualidade da assistência prestada $^{1}$. A prática de higienização das mãos (HM) é, desde o século XIX, reconhecida como medida importante para prevenir infecções ${ }^{1}$. Estudos de Semmelweiss comprovaram a sua implicação nas taxas de mortalidade por febre puerperal, em que, em razão da não higienização das mãos pelos profissionais, o óbito materno se mantinha acima de $18 \%$ no Hospital Geral de Viena ${ }^{1,2}$.

O Centers for Disease Control and Prevention (CDC), dos Estados Unidos da América), uma das principais agências norteadoras das práticas de HM, publica guias orientando essa medida desde a década de $1970^{3-6}$. As infecções de sítio cirúrgico (ISC) são complicações que podem ocorrer nos procedimentos cirúrgicos, manifestando-se na incisão ou no órgão manipulado. No Brasil, as ISC ocupam o terceiro lugar entre as IRAS, acometendo entre 14 e $16 \%$ dos pacientes hospitalizados $^{5}$. Dados americanos apontam que 500 mil pacientes são afetados por ISC, com elevação significativa do tempo de internação e dos custos hospitalares, além dos prejuízos físico, emocional e financeiro para os pacientes e suas famílias ${ }^{6}$.

A ISC é uma complicação multifatorial, dependente de fatores ligados ao paciente, à equipe e ao procedimento cirúrgico $^{3}$. Em relação ao ato operatório, pode-se destacar a antissepsia das mãos da equipe como um dos fatores mais relevantes, pois atua na redução da carga microbiana das mãos ${ }^{3-9}$. A utilização de escovas impregnadas com antissépticos representa o método tradicional de higienização pré-cirúrgica das mãos ${ }^{10}$, porém as preparações alcoólicas têm sido amplamente recomendadas pela Organização Mundial da Saúde (OMS), dadas as suas vantagens, como menor tempo despendido para a preparação das mãos, menos efeitos dermatológicos, economia na utilização de recursos, como água e compressas, além da redução de resíduos ${ }^{10}$.

Em estudo sobre implantação de antisséptico alcoólico em substituição à escovação, no Centro Cirúrgico (CC) de hospital privado da Região Sul do Brasil, observou-se que a adesão à técnica correta, com o uso da solução alcoólica pelos cirurgiões e instrumentadores, foi de $35,8 \%{ }^{11}$. O tempo de fricção foi a principal falha observada $(94,2 \%)^{11}$, pois esta era realizada em intervalo menor que o recomendado pelo fabricante do produto (2 minutos). Na literatura, são escassas as referências que sugerem tempos menores de antissepsia alcoólica. Esses fatores motivaram a realização do presente estudo.

\section{OBJETIVO}

Avaliar a redução microbiana da antissepsia cirúrgica das mãos com preparação alcoólica, realizada pelos cirurgiões em diferentes tempos, sob condições práticas de uso no CC.

\section{MÉTODO}

Estudo do tipo prevalência, pragmático, de campo, realizado no CC de hospital privado da região Sul do Brasil, após aprovação do Comitê de Ética em Pesquisa. Realizaram-se o processamento das culturas e a contagem microbiana no Laboratório de Microbiologia da Universidade Federal de Ciências da Saúde de Porto Alegre (UFCSPA). A coleta de dados ocorreu durante o período de abril a junho de 2017. Para a pesquisa, utilizou-se como referencial o Strengthening the Reporting of Observational Studies in Epidemiology (STROBE) de estudos observacionais.

A amostra, não probabilística, constituiu-se de médicos-cirurgiões atuantes na instituição. Coletaram-se amostras 
das mãos de 54 cirurgiões selecionados aleatoriamente, de forma não intencional, antes da realização da cirurgia. Os critérios de inclusão foram aceitar participar da pesquisa, assinar Termo de Consentimento Livre e Esclarecido (TCLE), optar por realizar preparo cirúrgico das mãos com solução alcoólica, fazer antissepsia cirúrgica das mãos com a técnica (passo a passo) correta, não utilizar adornos nas mãos (como anéis, relógios ou pulseiras), nem possuir lesões nas mãos. Excluíram-se da amostra os cirurgiões que realizaram antissepsia para procedimentos de emergência.

Considerando o poder de $90 \%$ para testar a diferença entre as médias de contaminação nos momentos 1 e 2 do procedimento, estimou-se que a amostra deveria ser composta de 44 cirurgiões, adotando-se $\mathrm{p}<0,05$.

Os participantes deste estudo assinaram o TCLE. A pesquisa foi submetida e aprovada pelo Comitê de Ética e Pesquisa da instituição hospitalar privada, sob Certificado de Apresentação para Apreciação Ética (CAAE): 59234816.9.3001.5328 e instituição de ensino superior federal, sob CAAE: 59234816.9.0000.5345.

O produto avaliado no teste foi o Purell Surgical Scrub® (gel), produzido por GOJO Industries Inc., disponibilizado na instituição para antissepsia cirúrgica das mãos dos profissionais. Sua formulação é composta de etanol $70 \%$ (peso/peso - p/p) sob a forma de gel. A coleta de dados ocorreu por observação não participante e realização de culturas microbiológicas.

Realizou-se observação direta da antissepsia cirúrgica das mãos com preparação alcoólica para determinar o tempo do procedimento e verificar a adesão à técnica padronizada, utilizando instrumento para registro da caracterização do profissional, da especialidade e do tempo de execução da técnica. Não houve interferência da pesquisadora na técnica utilizada para a antissepsia cirúrgica alcoólica realizada pelo cirurgião, porém, houve a orientação de que ele deveria proceder à lavagem simples das mãos. Considerou-se a antissepsia cirúrgica alcoólica adequada quando os movimentos foram executados conforme preconizado pela $\mathrm{OMS}^{10}$, a qual, suscintamente, orienta a higiene dos leitos subungueais, seguidos dos dedos, da palma e do dorso de uma das mãos e antebraço, seguidos dos mesmos procedimentos na mão oposta. A adequação à técnica correta baseou-se nas recomendações do fabricante, com tempo preconizado de 120 segundos, ou 2 minutos.

Realizaram-se as amostras culturais após a lavagem, visando determinar a flora microbiana basal do profissional, e após a antissepsia cirúrgica alcoólica das mãos, para identificar a redução da contagem microbiana imediata.

Para remover a flora residente das mãos, o cirurgião realizou a lavagem simples das mãos utilizando o sabão antisséptico disponibilizado no CC, à base de triclosan, com a técnica padronizada na instituição. Para a determinação dos valores de unidades formadoras de colônias (UFC) nos dois momentos de coleta (pré e pós-antissepsia), as falanges distais de ambas as mãos foram friccionadas durante 1 minuto em placa de Petri contendo $10 \mathrm{~mL}$ de caldo soja tripticaseína (CST) e neutralizadores (polissorbato $80,3 \%$, saponina $3 \%$, histidina $0,1 \%$ e cisteína $0,1 \%$ ). Uma alíquota de $0,1 \mathrm{~mL}$ desse caldo, assim como a mesma quantidade do caldo diluído em $1 \mathrm{~mL}$ (1:10) e $0,1 \mathrm{~mL}$ dessa última diluição em $1 \mathrm{~mL}$ (1:100), foi semeada em placa de ágar soja tripticaseína (AST). O intervalo entre a coleta e a semeadura não excedeu 30 minutos. As placas foram transportadas até o laboratório da Universidade para incubação a $37^{\circ} \mathrm{C} \pm 2^{\circ} \mathrm{C}$ e lidas após 24 horas.

Selecionou-se essa metodologia com base em estudos que utilizaram o método europeu EN-12054 $4^{12,13}$, porém com adaptações:

- a metodologia propõe a utilização de contaminação intencional das mãos com cepas de Escherichia coli, entretanto, na pesquisa realizada, avaliou-se a microbiota em condições reais, no ambiente de atuação dos profissionais;

- a comparação proposta no estudo não foi realizada entre o produto antisséptico e o de referência, como propõe a metodologia. Compararam-se as contagens microbianas das mãos higienizadas com o mesmo produto, porém com tempos diferentes de execução do procedimento;

- incubaram-se as placas s por 24 horas a $37^{\circ} \mathrm{C} \pm 2^{\circ} \mathrm{C}$.

Para cada diluição, identificou-se o número de UFC e multiplicou-se esse valor pelo fator de diluição, a fim de obter o número de UFC por $\mathrm{mL}$ da amostra líquida. Para fins de comparação dos períodos pré e pós-antissepsia, utilizaram-se as contagens de UFC na diluição de 1:10. Estabeleceu-se a diferença entre as contagens pré e pós-antissepsia e, depois, a sua representação em percentual e em fator de redução logarítmica $\left(\log _{10}\right)$. Categorizaram-se os percentuais de redução em redução leve (até 50\%), moderada (50 a 80\%) e alta (acima de $80 \%$ ). Essa categorização não encontra referenciais na literatura e foi proposta com o intuito de possibilitar comparações entre as reduções, estratificando-as por categorias de tempo. Classificaram-se os resultados de redução microbiana nas três categorias de tempos de execução do procedimento: até 90 segundos, de 90 a 180 segundos e acima de 180 segundos.

Este trabalho foi apresentado de forma oral na sessão educativa da AORN Global Surgical Conference \& Expo, 
nos Estados Unidos da América em 2019, com o título "A comparison of microbial counts with different procedure lengths of alcoholic surgical hand antisepsis".

\section{RESULTADOS}

Efetuaram-se coletas de 54 sujeitos, das quais se descartaram nove $(16,7 \%)$ por terem demonstrado suspeita de contaminação, evidenciada pelo número expressivo de UFC nas amostras pós-antissepsia. Assim, incluíram-se 45 sujeitos na pesquisa.

Em relação à distribuição dos cirurgiões quanto à especialidade cirúrgica, prevaleceram: ortopedia e traumatologia $(\mathrm{n}=14$, $31 \%)$; cirurgia geral $(\mathrm{n}=12,27 \%)$; otorrinolaringologia $(\mathrm{n}=5,11 \%)$; cirurgia vascular ( $n=4,9 \%)$; urologia $(n=3,7 \%)$; ginecologia $(\mathrm{n}=3,7 \%)$; cirurgia plástica $(\mathrm{n}=2,4 \%)$; e neurocirurgia $(\mathrm{n}=2,4 \%)$.

Tabela 1. Análise descritiva da redução logarítmica da contagem bacteriana e desvio padrão pré-antissepsia e pós-antissepsia das mãos pelos cirurgiões.

\begin{tabular}{|c|c|c|c|c|}
\hline & & \multicolumn{3}{|c|}{ Média $\log _{10}(\mathrm{DP})$} \\
\hline & & $\begin{array}{c}\text { Contagem } \\
\text { inicial } \\
\text { bacteriana }\end{array}$ & $\begin{array}{c}\text { Contagem } \\
\text { final } \\
\text { bacteriana }\end{array}$ & $\begin{array}{l}\text { Fator de } \\
\text { Redução } \\
\text { (pré/pós) }\end{array}$ \\
\hline \multirow{3}{*}{ 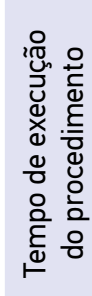 } & $\begin{array}{l}\text { Até } 90 \mathrm{seg} \\
\qquad \mathrm{N}=18\end{array}$ & $\begin{array}{c}1,53 \\
(0,60)\end{array}$ & $\begin{array}{c}1,74 \\
(0,60)\end{array}$ & $\begin{array}{c}0,79 \\
(0,54)\end{array}$ \\
\hline & $\begin{array}{c}\text { De } 90 \text { a } 180 \mathrm{seg} \\
\quad \mathrm{N}=22\end{array}$ & $\begin{array}{c}178 \\
(0,88)\end{array}$ & $\begin{array}{c}0,67 \\
(0,69)\end{array}$ & $\begin{array}{c}1,12 \\
(0,86)\end{array}$ \\
\hline & $\begin{array}{c}\text { Acima de } \\
180 \mathrm{seg} \\
\mathrm{N}=5\end{array}$ & $\begin{array}{c}1,40 \\
(0,72)\end{array}$ & $\begin{array}{c}0,48 \\
(0,66)\end{array}$ & $\begin{array}{c}0,92 \\
(0,90)\end{array}$ \\
\hline
\end{tabular}

DP: desvio padrão.
Das 45 amostras consideradas válidas, em sete (15,5\%) não se observou redução da contagem bacteriana após a antissepsia alcoólica. Para cada amostra, calculou-se o fator de redução logarítmica da contagem microbiana, subtraindo-se o valor da contagem pós-antissepsia da amostra pré-antissepsia, obtendo-se os dados apresentados na Tabela 1.

Considerando-se apenas as amostras nas quais se observou redução da contagem microbiana $(\mathrm{n}=38)$, calculou-se o percentual de redução microbiana das amostras pós-antissepsia, em relação às coletas pré-antissepsia, e realizou-se a classificação de acordo com a expressão dessa redução, obtendo-se a distribuição apresentada na Figura 1.

A média de tempo de execução da técnica foi de $116 \pm 97$ segundos. Quanto à distribuição da redução da contagem microbiana agrupada por categoria de tempo de execução da técnica, os dados estão representados e descritos na Tabela 2.

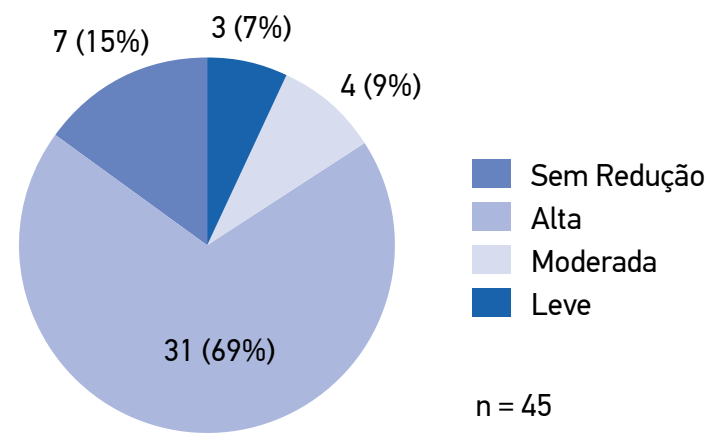

Figura 1. Amostras conforme categoria de redução da contagem microbiana pós-antissepsia das mãos pelos cirurgiões.

Tabela 2. Classificação da redução da contagem microbiana conforme o tempo de antissepsia das mãos pelos cirurgiões.

\begin{tabular}{|c|c|c|c|c|c|}
\hline \multicolumn{5}{|c|}{ Classificação da redução da contagem microbiana } \\
\hline Intervalos de execução da técnica & Leve & Moderada & Alta & Sem redução & Total \\
\hline$<9$ segundos (n. absoluto) & 2 & 1 & 12 & 4 \\
\hline$\%$ do intervalo de tempo de execução & $11 \%$ & $5 \%$ & $63 \%$ & $21 \%$ & 19 \\
\hline$\%$ do total da amostra & $4 \%$ & $2 \%$ & $27 \%$ & $9 \%$ & 3 \\
\hline $90-180$ segundos (n. absoluto) & 0 & 2 & 16 & $14 \%$ \\
\hline$\%$ do intervalo de tempo de execução & $0 \%$ & $10 \%$ & $76 \%$ & $7 \%$ \\
\hline$\%$ do total da amostra & $0 \%$ & $4 \%$ & $36 \%$ & 0 \\
\hline$>180$ segundos (n. absoluto) & 1 & 1 & 3 & $0 \%$ \\
\hline$\%$ do intervalo de tempo de execução & $20 \%$ & $20 \%$ & $60 \%$ & 5 \\
\hline Total & $2 \%$ & $2 \%$ & $7 \%$ & $0 \%$ \\
\hline
\end{tabular}


Tabela 3. Classificação da redução da contagem microbiana pelo tempo de antissepsia das mãos pelos cirurgiões, após reagrupamento das categorias de tempo.

\begin{tabular}{|c|c|c|c|c|c|}
\hline \multicolumn{6}{|c|}{ Classificação dos casos com redução } \\
\hline Intervalos de execução da técnica & Leve & Moderada & Alta & Sem redução & Total \\
\hline$\leq 90$ segundos (n. absoluto) & 2 & 1 & 12 & 15 & \\
\hline$\%$ do intervalo de tempo de execução & $13,30 \%$ & $6,70 \%$ & $80,00 \%$ & $100,00 \%$ & \\
\hline$\%$ do total da amostra & $5,30 \%$ & $2,60 \%$ & $31,60 \%$ & 39,50 & \\
\hline$>90$ segundos (n. absoluto) & 1 & 3 & 19 & 23 & \\
\hline$\%$ do intervalo de tempo de execução & $4,30 \%$ & $13,00 \%$ & $82,60 \%$ & $100,00 \%$ & \\
\hline$\%$ do total da amostra & $2,60 \%$ & $7,90 \%$ & $50,00 \%$ & $60,50 \%$ & \\
\hline Total & 3 & 4 & 31 & 38 & \\
\hline
\end{tabular}

Os achados apresentam-se heterogêneos na sua distribuição, o que torna frágeis as comparações entre as categorias apresentadas. Por esse motivo, reagruparam-se as categorias de tempo em $\leq 90$ segundos e $>90$ segundos para tornar consistentes os cotejos (Tabela 3). Da mesma forma, excluíram-se da análise as situações nas quais não houve redução microbiana, totalizando 38 procedimentos.

No intuito de verificar a equivalência das proporções ou independência entre os tempos de execução da técnica e o desfecho analisado (redução da contagem microbiana), aplicou-se o teste $\chi^{2}$, confirmando que não houve associação significativa entre o tempo de execução do procedimento e a categoria de redução da contagem microbiana $\left(\chi^{2} 1,284 ; p=0,526\right)$.

\section{DISCUSSÃO}

Em relação à caracterização da amostra, as especialidades cirúrgicas participantes do estudo mostraram-se compatíveis com a distribuição da produção da instituição hospitalar. As amostras evidenciaram que em $15 \%$ ( $\mathrm{n}=7$ do total de 45 analisados) dos procedimentos não ocorreu redução da contagem bacteriana após a realização da técnica. Esse fato é preocupante, uma vez que a flora bacteriana transitória das mãos preparadas para o procedimento cirúrgico deve ser eliminada e a flora residente deve ser reduzida ao mínimo possível ${ }^{3}$.

A utilização de luvas estéreis configura barreira adicional para a passagem de bactérias das mãos para o sítio cirúrgico, porém as luvas estéreis apresentam taxa de perfuração em torno de $11 \%$, imperceptível pela equipe cirúrgica entre 31 e $34 \%$ dos casos em cirurgias com duração de mais de 2 horas $^{14,15}$. A mediana de tempo de execução da técnica de 97 segundos e o tempo médio de 116 segundos foram compatíveis com estudo finlandês, no qual se observou média de 110 segundos, porém abaixo do tempo preconizado pelo fabricante ${ }^{16}$.

Ao realizar o agrupamento das frequências de tempo, observa-se similaridade entre o número de profissionais que realizou a técnica em 90 segundos $(\mathrm{n}=19)$ e em 90 a 180 segundos $(\mathrm{n}=21)$, tendo sido observada frequência menor na categoria acima de 180 segundos ( $\mathrm{n}=5$ ). Estudo mostra que, em $42 \%$ das observações realizadas, o tempo de antissepsia durou 180 segundos, diferentemente da porcentagem encontrada nesta pesquisa, de $11 \%$ $(\mathrm{n}=5)^{16}$. Ao considerar o tempo recomendado pelo fabricante, de 120 segundos, o estudo evidenciou apenas $40 \%$ (18/45) de adesão. Esses achados remetem a dificuldades da equipe cirúrgica em aderir à técnica de antissepsia preconizada. Considerando-se que os profissionais estavam sendo observados durante a realização do procedimento, deve-se admitir que o efeito Hawthorne (determina mudança de comportamento do sujeito quando sabe que está sendo observado) possa ter ocorrido. Logo, os resultados em relação à adesão ao tempo indicado podem ser piores no dia a dia. Estudo prévio conduzido na mesma instituição onde esse estudo se desenvolveu já havia demonstrado que o tempo era a principal falha observada na técnica de antissepsia realizada pelos cirurgiões ${ }^{11}$. Essa realidade também foi observada em outra pesquisa, na qual se reportou que $10 \%$ dos participantes realizavam a antissepsia cirúrgica alcoólica em menos de 60 segundos ${ }^{17}$.

Apesar de não se observar adequação quanto ao tempo recomendado para antissepsia, quando analisada a distribuição da amostra conforme categoria de redução da contagem microbiana, a maioria ( $82 \%$ ) obteve redução severa da contagem microbiana após a antissepsia.

Observam-se, entre os profissionais que realizaram a antissepsia em até 90 segundos, $80 \%(\mathrm{n}=12$, do total de 15$)$ de reduções severas, similar à frequência encontrada na categoria acima de 90 segundos, 82,6\% ( $\mathrm{n}=19$, do total de 23$)$. A análise $\chi^{2}$ confirmou 
ausência de associação entre o tempo de execução do procedimento e a categoria de redução microbiana $\left(\chi^{2} 1,284 ; p=0,526\right)$. Apesar de a OMS não recomendar o tempo de 90 segundos e este também não estar referenciado na norma europeia (EN-12791) $)^{3,18,19}$, estudo demonstrou que 90 segundos poderiam ser equivalentes em eficácia a 2 ou 3 minutos, mediante a utilização de formulações contendo isopropanol e n-propanol, além de etilsulfato de mecetrônio, o que não corresponde ao produto em teste ${ }^{20}$.

Quando a técnica foi desempenhada em mais de 180 segundos, todas as amostras apresentaram redução de contagem bacteriana, o que não ocorreu em tempos menores. Esse achado pressupõe que, se a técnica e o tempo recomendados forem seguidos, existem maiores chances de haver redução bacteriana em comparação aos tempos menores, apesar de não ter sido evidenciada associação entre o tempo e a redução bacteriana. É necessário considerar que apenas cinco profissionais realizaram a antissepsia por mais de 180 segundos, o que limita o aproveitamento do dado.

O fator de redução logarítmica evidenciado no nosso estudo foi de 1,72 $\pm 0,74$, ou seja, acima do preconizado para estudos experimentais que visam validar produtos seguindo os preceitos da norma EN-12791. De acordo com essa norma, para ser considerado efetivo, um produto alcoólico para antissepsia cirúrgica das mãos deve apresentar valores não significativamente maiores do que o produto-referência que consta na regulamentação (n-propanol 60\%), imediatamente após a sua aplicação e após 3 horas. Nessa normatização, a mediana de redução logarítmica apresentada foi de 3,27 $\pm 1,13$ para aquela formulação específica de álcool. Em contrapartida, o estudo identificou que, para formulações contendo etanol 70\%, esperam-se reduções na ordem de 1 a $1,3 \log 10$ da microbiota residente ${ }^{21,22}$. Portanto, em relação ao produto referenciado na norma, os valores de redução encontrados nesse teste não foram satisfatórios. Porém, em comparação com o estudo citado, que avaliou unicamente produtos à base de etanol, nossos resultados mostraram-se aceitáveis.

Esta pesquisa procurou identificar, em condições reais de utilização, qual o efeito do produto testado na redução da população microbiana das mãos dos cirurgiões e relacioná-lo com o tempo de execução do procedimento. Os resultados demonstram não haver associação significativa entre o tempo de execução da antissepsia e a categoria de redução microbiana das mãos. Entretanto, quando o tempo de antissepsia foi maior que 180 segundos, não houve casos sem redução, como os que ocorreram nos outros tempos. Com esse dado, pode-se inferir que, quanto maior o tempo, maior a redução microbiológica (severa) em percentual absoluto, entretanto $\operatorname{com} \chi^{2}$ não significativo.
O presente estudo apresenta algumas limitações, entre as quais se podem destacar: o volume de solução alcoólica empregada pelo profissional não foi controlado, o que pode ter influenciado os valores de contagem microbiana das mãos após a antissepsia. Do mesmo modo, o efeito Hawthorne pode ter influenciado a técnica empregada pelos cirurgiões para o preparo das mãos, interferindo na qualidade e no tempo despendido ${ }^{23}$. Além disso, os resultados não podem ser generalizados, pois a amostra por especialidade não foi significativamente representativa da população de cirurgiões da instituição. Da mesma forma, testou-se apenas uma marca de solução alcoólica, o que impossibilita estender as conclusões a outros produtos disponíveis no mercado. Outra variável que pode ser considerada como limitante é o fato de que, embora o cálculo amostral seja adequado, os extratos gerados limitaram as comparações entre eles.

Este estudo contribui para demonstrar a importância do emprego de técnicas de antissepsia com os tempos validados e preconizados pelos fabricantes para a redução da carga microbiana das mãos. A realização efetiva da técnica possibilita a realização do procedimento cirúrgico seguro, estabelecendo a segurança da assistência ao paciente. Dessa forma, a enfermagem, no seu papel ativo na assistência para a promoção do cuidado isento de riscos, poderá, por meio da prática baseada em evidências, capacitar e estimular os demais profissionais a realizarem a técnica correta de antissepsia das mãos.

\section{CONCLUSÃO}

Ao avaliar a antissepsia cirúrgica das mãos com preparação alcoólica realizada pelos cirurgiões em diferentes tempos, nas condições práticas de uso no CC, evidenciou-se redução da contagem bacteriana na maioria dos casos, ao se analisar a técnica em $\leq 90$ segundos e $>90$ segundos; entretanto, não houve diferença estatisticamente significativa. Quando a técnica foi realizada em mais de 180 segundos, todas as amostras apresentaram redução de contagem bacteriana, o que não ocorreu em menores tempos. Os resultados evidenciam que, quando a técnica e o tempo recomendados são seguidos conforme preconizado pela OMS, melhores resultados de redução bacteriana ocorrem, em comparação aos tempos menores. Estudos experimentais, com adequado controle das variáveis, se fazem necessários para confirmar essa hipótese.

A média de tempo de antissepsia encontrada no estudo foi de 116 segundos, abaixo do preconizado pela OMS. O tempo de execução da técnica permanece como grande desafio na abordagem da antissepsia cirúrgica alcoólica das mãos. 


\section{REFERÊNCIAS}

1. Dutra GG, Costa MP, Bosenbecker EO, Lima LM, Siqueira HCH, Cecagno D. Nosocomial infection control: role of the nurse. J Res Fundam Care Online. 2015;7(1):2159-68. http://doi.org/10.9789/21755361.2015.v7i1.2159-2168

2. Birgand G, Lepelletier D, Baron G, Barrett S, Breier A-C, Buke C, et al. Agreement among healthcare professionals in ten European countries in diagnosing case-vignettes of surgical site infections. PLoS One. 2013;8(7):e68618. https://doi.org/10.1371/journal.pone.0068618

3. World Health Organization (WHO). Global guidelines on the prevention of surgical site infection [Internet]. Genebra: WHO; 2016 [acessado em 30 abr. 2018]. Disponível em: https://www.who.int/gpsc/ssi-guidelines/en/

4. Boyce JM, Pittet D, Healthcare Infection Control Practices Advisory Committee, HICPAC/SHEA/APIC/IDSA Hand Hygiene Task Force. Guideline for hand hygiene in health-care settings: recommendations of the Healthcare Infection Control Practices Advisory Committee and HICPAC/SHEA/APIC/IDSA Hand Hygiene Task Force. MMWR Recomm Rep [Internet]. 2002 [acessado em 12 jun. 2019];51(RR-16):1-45. Disponível em: https://www.ncbi.nlm.nih.gov/pubmed/12418624

5. Brasil. Agência Nacional de Vigilância Sanitária (ANVISA). Medidas de prevenção de infecção relacionada à assistência à saúde [Internet]. Brasília: ANVISA; 2017 [acessado em 17 fev. 2020]. Disponível em: http://biblioteca.cofen.gov.br/medidas-de-prevencao-de-infeccaorelacionada-a-assistencia-a-saude/

6. Anderson DJ, Podgorny K, Berríos-Torres SI, Bratzler DW, Dellinger $E P$, Greene L, et al. Strategies to prevent surgical site infections in acute care hospitals: 2014 update. Infect Control Hosp Epidemiol. 2014;35(6):605-27. https://dx.doi.org/10.1086\%2F676022

7. Berríos-Torres SI, Umscheid CA, Bratzler DW, Leas B, Stone EC, Kelz RR, et al. Centers for Disease Control and Prevention (CDC). The hospital infection control practices advisory committee: Guideline for prevention of surgical site infection. JAMA Surg. 2017;152(8):78491. https://doi.org/10.1001/jamasurg.2017.0904

8. Alexander JW, Solomkin JS, Edwards MJ. Updated recommendations for control of surgical site infection. Ann Surg. 2011;253(6):1082-93. https://doi.org/10.1097/SLA.0b013e31821175f8

9. Widmer AF, Rotter M, Voss A, Nthumba P, Allegranzi B, Boyce J, et al. Surgical hand preparation: state-of-the-art. J Hosp Infect. 2010;74(2):112-22. https://doi.org/10.1016/j.jhin.2009.06.020

10. World Health Organization (WHO). WHO guidelines on hand hygiene in health care. First global patient safety challenge clean care is safer care [Internet]. Genebra: WHO; 2009 [acessado em 30 abr. 2018]. Disponivel em: http://apps.who.int/iris/bitstream/10665/44102/1/97892 41597906_eng.pdf

11. Prates J, Monteiro AB, Lopes F, Stumpfs D, Guglielmi G, Narvaez G, et al. Implementação de antissepsia cirúrgica alcoólica nas mãos: relato de experiência. Rev SOBECC. 2016;21(2):116-21. https://doi. org/10.5327/Z1414-4425201600020009
12. Kawagoe JY. Higiene das mãos: comparação da eficácia antimicrobiana do álcool - formulação gel e líquida - nas mãos com matéria orgânica [tese]. São Paulo: Escola de Enfermagem da Universidade de São Paulo; 2004.

13. Barbadoro P, Martini E, Savini S, Marigliano A, Ponzio E, Prospero E, et al. In vivo comparative efficacy of three surgical hand preparation agents in reducing bacterial count. J Hosp Infect. 2014;86(1):64-7. https://doi.org/10.1016/j.jhin.2013.09.013

14. Oliveira AC, Gama CS. Surgical antisepsis practices and use of surgical gloves as a potential risk factors to intraoperative contamination. Esc Anna Nery. 2016;20(2):370-7. https://doi. org/10.5935/1414-8145.20160051

15. Misteli H, Weber WP, Reck S, Rosenthal R, Zwahlen M, Fueglistaler $P$, et al. Surgical glove perforation and the risk of surgical site infection. Arch Surg. 2009;144(6):553-8. https://doi.org/10.1001/ archsurg. 2009.60

16. Laurikainen E, Rintala E, Kaarto AM, Routamaa M. Adherence to surgical hand rubbing directives in a hospital district of Southwest Finland. Infect Dis. 2016;48(2):116-21. https://doi.org/10.3109/237 44235.2015.1089591

17. Oriel BS, Chen Q, Itani KMF. The impact of surgical hand antisepsis technique on surgical site infection. Am J Surg. 2017;213(1):24-9. https://doi.org/10.1016/j.amjsurg.2016.09.058

18. Widmer AF. Surgical hand hygiene: scrub or rub? J Hosp Infect. 2013;83(Supl. 1):S35-9. https://doi.org/10.1016/ S0195-6701(13)60008-0

19. European Committee for Standardization. CSN EN-12791. Chemical disinfectants and antiseptics: surgical hand disinfection. Test method and requirements (phase2/step2). Bruxelas: European Committee for Standardization; 2005 [acessado em 22 abr. 2019]. Disponível em: https://standards.globalspec.com/std/13065377/ EN\%2012791

20. Kampf G, Goroncy-Bermes P, Fraise A, Rotter M. Terminology in surgical hand disinfection: a new Tower of Babel in infection control. J Hosp Infect. 2005;59(3):269-71. https://doi.org/10.1016/j.jhin.2004.09.020

21. Suchomel M, Rotter M. Ethanol in pre-surgical hand rubs: concentration and duration of application for achieving European Norm EN-12791. J Hosp Infect. 2011;77(3):263-6. https://doi. org/10.1016/j.jhin.2010.10.014

22. Kampf G, Kramer A, Suchomel M. Lack of sustained efficacy for alcohol-based surgical hand rubs containing residual active ingredients according to EN-12791. J Hosp Infect. 2017;95(2):163-8. https://doi. org/10.1016/j.jhin.2016.11.001

23. Berthelot JM, Nizard J, Maugars Y. The negative Hawthorne effect: explaining pain over expression. Joint Bone Spine. 2019;86(4):4459. https://doi.org/10.1016/j.jbspin.2018.10.003 